\author{
Matrin Hardmeier \\ Claudio Gobbi \\ Carlos Buitrago \\ Andreas Steck \\ Philippe Lyrer \\ Stefan Engelter
}

\section{Dissection of the internal carotid artery mimicking episodic cluster headache}

Received: 4 February 2006

Received in revised form: 1 April 2006

Accepted: 3 April 2006

Published online: 2 March 2007

Sirs: Internal carotid artery dissection (ICAD) is one of the most frequent causes of stroke in young patients [1,2]. Diagnosis may be delayed by misinterpreting local signs of dissection. Typical features of cluster headache $(\mathrm{CH})$ have rarely been reported as presenting symptoms of ICAD [3-7]. Our case shows that subtle clinical features may point to symptomatic forms of $\mathrm{CH}$, and therefore both history taking and clinical examination must be particularly accurate.

Three weeks prior to admission, a 38-year-old man had a first attack of severe left-sided retroorbital pain extending into the

Dr. M. Hardmeier, MD ( $\square)$

Prof. C. Gobbi · Prof. A. Steck

Prof. P. Lyrer · S. Engelter, MD

Dept. of Neurology

University Hospital Basel Petersgraben 4, 4031 Basel

Switzerland

Tel.: +41-61/265-4151

Fax: +41-61/265-4100

E-Mail: mhardmeier@uhbs.ch

Prof. C. Buitrago, MD

Division of Neuroradiology

Dept. of Diagnostic Radiology

University Hospital Basel

Petersgraben 4, 4031

Basel, Switzerland mouth and ear, fluctuating over three days with pain maximum in the evening. He noted nasal congestion, tearing and hanging of the left eyelid. The pain subsided; however, mild ear pain persisted. An additional pain attack occurred one week later, in the evening, lasting for several hours. The history was negative for headache. A first episode of $\mathrm{CH}$ was suspected by his general practitioner. Oral sumatriptan prompted no relief. Thoracic CT was ordered to exclude a mass lesion in the lung apex and ocular pressure was found to be normal. On admission, the main complaint was a new attack of severe left-sided retroorbital and temporal pain. On examination the patient had hyperlacrimation, conjunctival injection and Horner's syndrome on the left without any further cranial nerve abnormalities. Oxygen inhalation and local nasal lidocaine were not effective, nasal sumatriptan resulted in partial relief. Neurosonography revealed a resistance flow pattern of the left distal internal carotid artery (ICA) without signs of atherosclerosis. Magnetic resonance imaging (MRI) and angiography (MRA) of the brain and neck demonstrated intramural haematoma and stenosis of the left distal ICA (Fig. 1), but no ischaemic lesions.

Based on these findings we diagnosed a left ICAD. Treatment consisted of acetylsalicylic acid (ASA) $100 \mathrm{mg}$ daily for stroke prevention [8] and verapamil $240 \mathrm{mg}$ daily for prophylaxis of pain attacks. The attacks disappeared within two weeks, but a moderate continuous pain persisted in the left lower face. Clinical signs of ICAD are often dissociated with initial pain and local signs followed by retinal or cerebral ischaemic events [1]. In a series of 65 ICAD patients, pain was the presenting symptom in $58.5 \%$, typically unilateral and localized, a painful Horner's syndrome was the initial sign in $29 \%$, in two cases, pain mimicked $\mathrm{CH}$ [2]. Five similar cases have been reported [3-7]: in all Horner's syndrome persisted in pain free intervals, autonomic parasympathetic signs variably included lacrimation, conjunctival injection and nasal congestion, duration and character of pain was less stereotyped than in $\mathrm{CH}$.

In ICAD, Horner's syndrome is secondary to vessel wall injury affecting the pericarotid sympathetic nerve fibers [1]. The pain of dissection may trigger a physiological trigeminal-autonomic reflex in susceptible patients, resulting in parasympathetic symptoms. Experimentally, this reflex can be activated by painful stimulation of the first trigeminal branch with injection of capsaicin inducing ipsilateral parasympathetic activation as measured by vasodilatation of the ICA [9]. In $\mathrm{CH}$ it is hypothesized that increased susceptibility to trigeminal input or increased parasympathetic outflow from the brain stem activate the trigeminalautonomic reflex during an acute attack [10].

In patients with typical pain and autonomic features suggesting $\mathrm{CH}$ persistent Horner's syndrome, absence of pain free periods, variability in both pain attack duration and pain characteristics, as in our case, should raise suspicion of ICAD. Clinical features alone may not reliably distinguish primary $\mathrm{CH}$ from symptomatic forms of $\mathrm{CH}$. Neurosonography as a screening tool [11] and brain MRI with contrast-enhanced MRA for confirmation of the diagnosis are useful in these patients. Treatment recommendations of ICAD are not based on controlled-randomized 
Fig. 1 Axial T1 weighted MRI at the level of the skull base without $(A)$ and with fat suppression combined with cranial-caudal saturation (B) show intramural haematoma (arrows) in the distal extracranial part of the left internal carotid artery. Contrast enhanced MR-angiography (C) depicts marked longitudinal stenosis of the left internal carotid artery (circle) trials $[1,8]$. There is still a debate, whether ASA is sufficient or anticoagulants are needed [12-14].

\section{References}

1. Schievink WI (2001) Spontaneous dissection of the carotid and vertebral arteries. N Eng J Med 344:898-906

2. Biousse V, D'Anglejan-Chatillon J, Massiou H, Bousser MG (1994) Head pain in non-traumatic carotid artery dissection: a series of 65 patients. Cephalalgia 14:33-36

3. Rosebraugh J, Griebel DJ, DiPette DJ (1997) A case report of carotid artery dissection presenting as cluster headache. Am J Med. 102:418-419

4. Leira EC, Cruz-Flores S, Leacock RO, Abdulrauf SI (2001) Sumatriptan can alleviate headaches due to carotid artery dissection. Headache 41:590-591
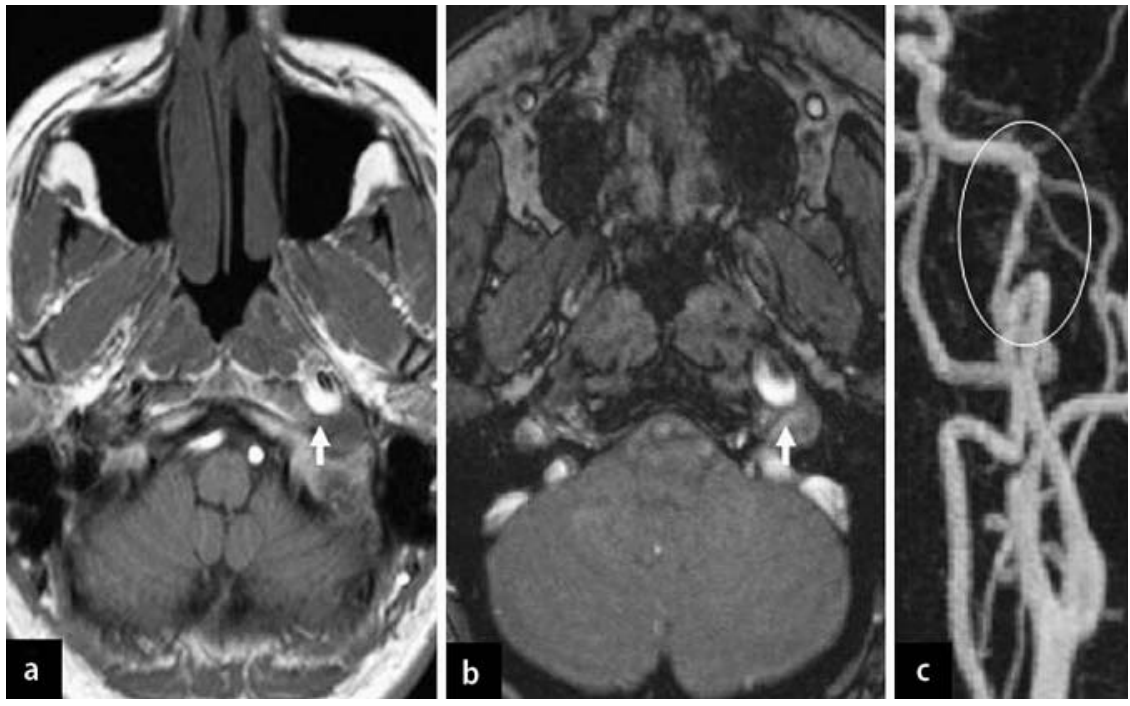

5. Mainardi F, Maggioni F, Dainese F, Amista P, Zanchin G (2002) Spontaneous carotid artery dissection with cluster-like headache. Cephalalgia 22:557-559

6. Frigerio S, Buhler R, Hess CW, Sturzenegger M (2003) Symptomatic cluster headache in internal carotid artery dissection - consider anhidrosis. Headache 43:896-900

7. Hannerz J, Arnardottir S, Bro Skejo HP, Lilja JA, Ericson K (2005) Peripheral postganglionic sympathicoplegia mimicking cluster headache attacks. Headache 45:84-86

8. Lyrer P, Engelter S (2003) Antithrombotic drugs for carotid artery dissection. Cochrane database Syst Rev. (3):CD000255

9. May A, Buchel C, Turner R, Goadsby PJ (2001) Magnetic resonance angiography in facial and other pain: neurovascular mechanisms of trigeminal sensation. J Cereb Blood Flow Metab 21:1171-6
10. Goadsby PJ (2002) Pathophysiology of cluster headache: A trigeminal autonomic cephalalgia. Lancet Neurol 1:251-257

11. Arning C (2005) Ultrasonographic criteria for diagnosing a dissection of the internal carotid artery. Ultraschall Med. 26:24-8

12. Norris WN (2005) Extracranial Arterial Dissection, anticoagulation is the treatment of choice: for. Stroke 36:2041-2042

13. Lyrer PA (2005) Extracranial Arterial Dissection, anticoagulation is the treatment of choice: against. Stroke 36:2043-2044

14. Donnan GA, Davis SM (2005) Extracranial Arterial Dissection, anticoagulation is the treatment of choice. Stroke 36:2045 